\title{
Problems encountered when assessing the technical condition of some types of industrial structures on the example of coal bunkers for a power boiler
}

\author{
Jan Kubica ${ }^{1, *}$, and Marta Kałuża ${ }^{1}$ \\ ${ }^{1}$ Silesian University of Technology, Department of Structural Engineering, 44-100 Gliwice, Poland
}

\begin{abstract}
The assessment of the technical condition of the structure in industrial facilities is sometimes very difficult, even for experienced construction specialists. First, this applies to facilities in which there are quite specific cubature constructions, as objects located in the coal mine facility, or coal-fired CHP plants. In the case of energy plants, such a typical construction that causes the most problems when assessing the technical condition is coal or fine coal storage tank usually in the form of bunker batteries supplying power boilers. In practice, access to the interior of such bunkers is possible only when the power unit is put out of service (boiler extinguish) in order to repair, upgrade or expand it. In presented paper on the example of two coal bunkers (from a battery consisting of four such constructions) of one of the power plants located in southern Poland, the authors want to present and discuss some specific problems that occurred in the assessment and analysis of the technical condition of this type of specific industrial structure.
\end{abstract}

\section{Introduction}

The issues of technical condition assessment of various types of industrial structures are well known and recognized. In this regard, many reports, guidelines and course manuals have already been published. There are also recommendations and standard provisions. First, two ISO standards must be kept in mind, in general, of all types of structures, including industrial and historic buildings. There are ISO 2394 [1] concerning general principles on reliability for structures and ISO13822 [2] on assessment of existing structures. Most of the guidelines and rules of conduct in assessing the condition of existing structures are based largely on the records of these two standards. There were also joint ventures created by international teams, as SAFERELNET: Thematic Network on Safety and Reliability of Industrial Products, Systems and Structures [3], or a handbook created as a result of the Czech-Norwegian grant, Sýkora et al. [4] and publication Brehm and Bolt [5]. Besides, important and helpful in the engineering practice from the range of assessing of the state of different types of structures is much more. From older publications, it is worth recalling the British books by Holland et

${ }^{*}$ Corresponding author: jan.kubica@polsl.pl 
al. [6] and Addleson [7]. From the new publications should not be omitted, including guidelines for evaluation of existing constructions, the German report Rücker et al. [8] and the Czech publication on basics for assessment of existing structures Holický et al. [9]. Increasingly, a probabilistic approach is applied in the process of assessing the condition of existing structures, which was clearly accepted in the 2001 Joint Committee on Structural Safety [10] report. In case of buildings and heritage structures, including industrial buildings two publications can be helpful, in particular the guidelines developed by the CIB W023 Commission [11] and the aforementioned Czech publication, Sýkora et al. [4].

In general, in the case of buildings or structures being during many years under exploitation in the industrial objects, damage can usually be divided into few main groups, namely:

1. damage caused by the improper designing and/or execution of the structure:

2. damages caused by overload or connected with a change in the nature of the load (e.g. due to change in utility functions or load of the object) or change in the static scheme (e.g. as a result of the reconstruction of the facility);

3. corrosive damage analysing in the field of a typical using (ageing of the components), long term action of aggressive environment or unexpected acting of harmful factors;

4. mechanical damage caused by the permanent action of material stored in the facility or some irregularities in the use of the object,

5. damage resulting from lack of a proper maintenance, inspections and repairs works.

The assessment of the technical condition of the structure in industrial facilities, compared to typical buildings and residential buildings, is sometimes very difficult, often quite a problem, even for an experienced construction specialist. First, this applies to industrial facilities in which there are quite specific cubature constructions. Such objects are, for example, located in the coal mine facility, or coal-fired CHP plants, and usually they containing coal or post-flotation mud, which unfortunately is still the main solution used in power engineering in Poland. In the case of energy plants, such atypical ones that cause the most problems when assessing the technical condition, there are coal or fine coal storage tanks usually in the form of bunker batteries supplying power boilers. In practice, access to the interior of such bunkers is possible only when the power unit is shut down from service (boiler extinguish) in order to repair, upgrade or expand it. Only then is it possible to temporarily empty the bunker, and sometimes even several bunkers from the battery, and to allow the assessment of the actual technical condition of both the inner surface of its walls and those built inside other structural elements. Typically, such structures are made as mixed reinforced concrete-steel, which often complicates the situation. It is very important here that these facilities are mostly used in very bad conditions and are exposed to aggressive factors, such as coal mine water being an integral part of extracted material. And it is with this case that the authors of the presented article came across.

On the example of two coal bunkers (from a battery consisting of four such constructions) of one of the heat and power plants located in southern Poland, the authors want to present and discuss some problems that occurred in the assessment and analysis of the technical condition of a specific industrial structure.

\section{Description of bunker's structure}

The bunkers were built in 1974, when a heating plant (with two water boilers) and a steam heating plant (with two steam boilers) was put into operation. The described facility handles OP-140 steam boilers. There are two identical tanks for raw coal (post-flotation mud).

Each of the bunkers was made as a 3-storey structure, which consists of a top backfill part (2-storey) and a bottom part shaped in the form of the three connected conical hoppers. The 
dimensions of the tank in the plan are $9.00 \times 12.00 \mathrm{~m}$, and its total height amounted to $12.25 \mathrm{~m}$, of which the backfill is $7.00 \mathrm{~m}$ height.

The bunker is made as a mixed structure, with a steel support system and concrete filling walls. The load-bearing system is constructed in the form of vertical and horizontal steel plain girders, braced with a grating made of angle steel sections - see Fig. 1. Locally, the bracing contains a steel sheet (as a filling). The elements are located in the plane of the upper covering slab.

To the plain girders, the system of steel I-sections - in the backfill part and L-sections within the hoppers is mounted transversally. The profiles are used to stiffen the steel sheet covering the bunkers from outside. The internal infill walls are made of reinforced concrete forming the inner plaster of the bunker's surface. In the upper part of the bunker, the concrete walls are additionally protected with the circumferential steel beams. In Fig. 2 the general view of the three hoppers with stiffening steel profiles are visible.

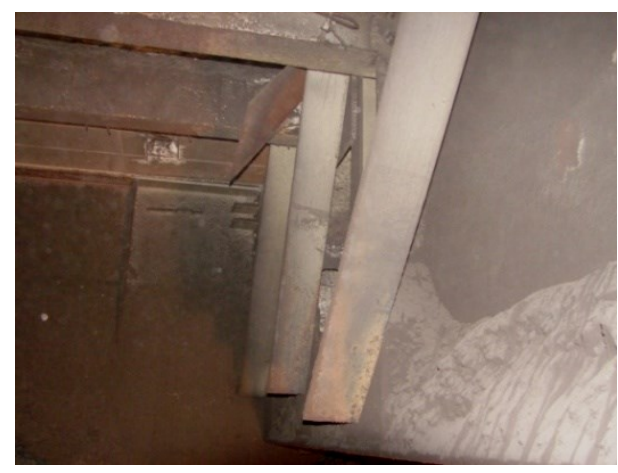

Fig. 1. The load-bearing system of the bunker.

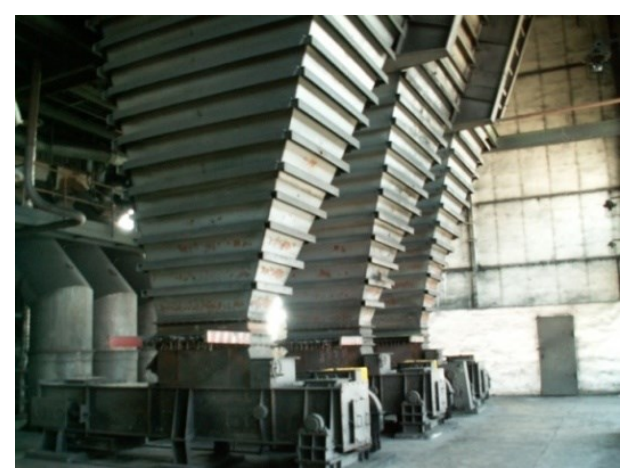

Fig. 2. Three hopper cover with the metal sheet and transverse stiffening profiles.

From the top, the bunker is closed with a concrete slab supported by the longitudinally steel beams, whose webs are covered with a concrete layer (Fig. 3). The beams are mounted to the load-bearing girders.

The bunker is filled from the top. In the covering concrete slab, on both sides of the charging conveyor there are longitudinal openings with steel grates (Fig. 3 and Fig. 4). The material from the hoppers is transferred via a worm gear to the crusher and mills.

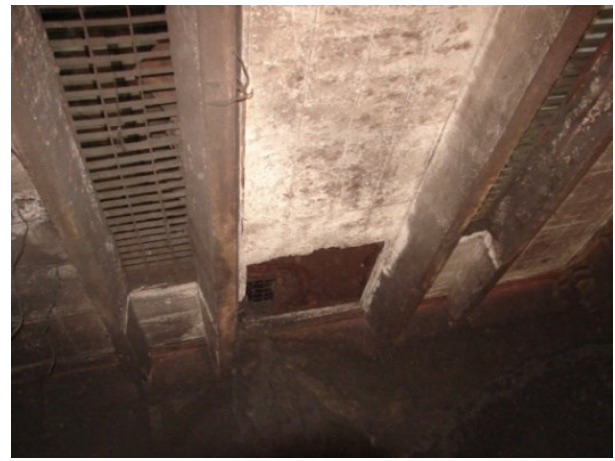

Fig. 3. Steel beams (with a concrete cover) serving as a support of the upper slab.

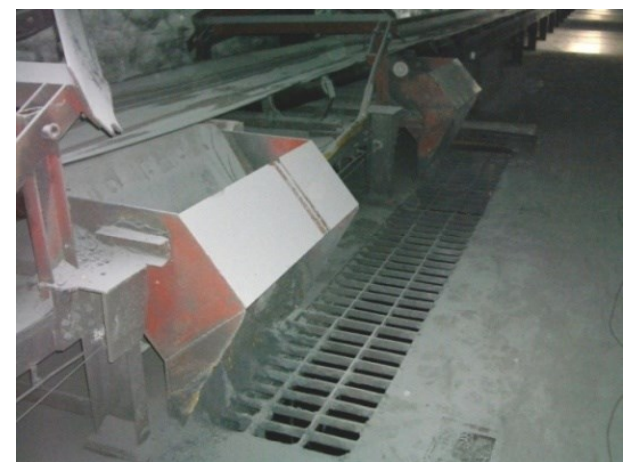

Fig. 4. The conveyer belt and charging opening. 


\section{Damage to the structural elements in analysed case}

The structure of the bunkers was subjected to external and internal inspections and studies of the technical condition. External inspection was made directly by the authors. However, the control of the interior was significantly impeded and requires introducing the climbing team, which had properly trained staff and appropriate equipment.

\subsection{Damage to interior of the bunker}

During the inspection carried out from the interior, many defects and damages were found around nearly all structural elements.

The largest damage was found on the circumferential steel beams, directly at the charging opening. Large steel sheet fragments, which protect the concrete filling wall, were destroyed. This situation was the result of the combination of two factors: the aggressive environment, which caused very strong pitting corrosion of the steel and mechanical action of the deposited material. The coal coming into the bunker always hit the same part on the wall, which was not capable of transferring such an impact force, especially when its structure is weaken by chemical interactions. The range of damage was huge, what is visible in Fig. 5a and 5b.

a)

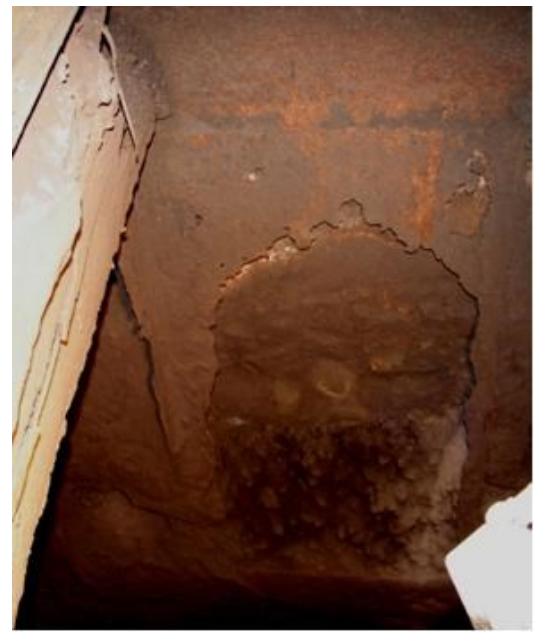

b)

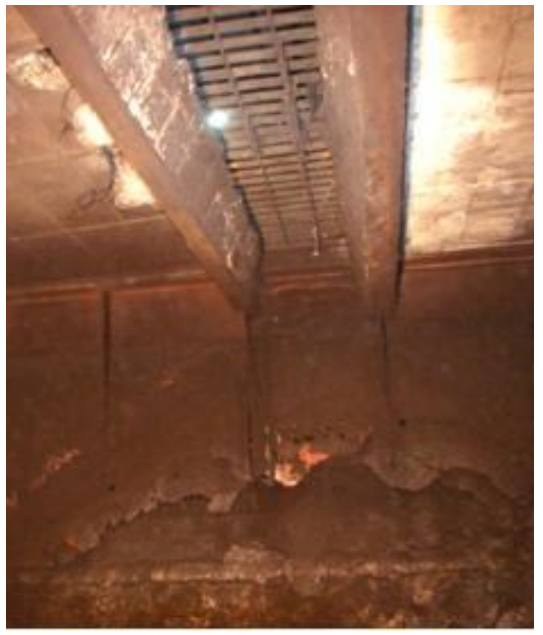

Fig. 5. Huge damage to the circumferential steel beam.

In the remaining parts of the steel beams almost no visible damages, except for slight surface corrosion were observed.

Unfortunately, for technical and technological reasons, analysed bunker was only partially emptied, and therefore only a part of the wall surface was available. Both mechanical and corrosive damage of the concrete wall was observed. There were numerous pits caused by the action of harmful factors, especially sulphate and chloride ions. These factors are usually contained in mine water [12], which is an inseparable part of the coal mining process.

It can be assumed that the condition of the walls within the hoppers (undiscovered part) is identical, because all surfaces of the bunker are exposed to the harmful factors, included in coal. 
a)

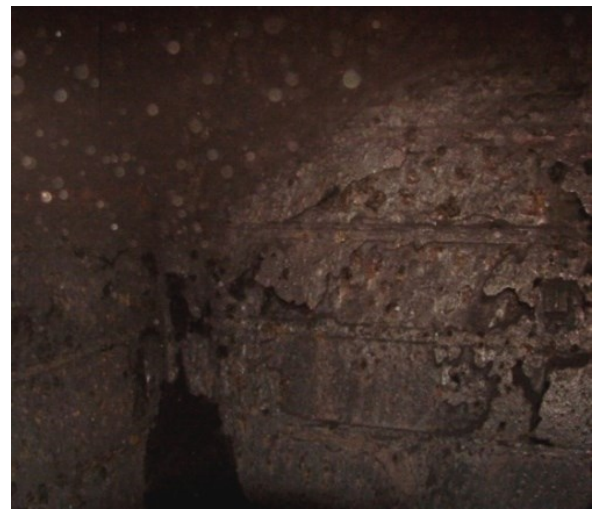

b)

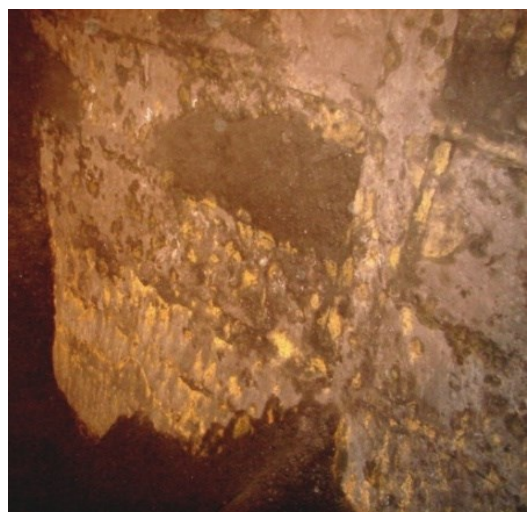

Fig. 6. Damage to the concrete walls: a) mechanical damage to the surface, b) surface and pitting corrosion.

The elements of load-bearing system (steel plain girders, sheets inside the bracing) indicate damage varying in intensity. Aggressive factors contained in coal water caused most often surface corrosion of the steel in places where the extracted coal does not remain permanently in place (elements have contact with coal water only when pouring material) Fig. 7a. Parts of the structure exposed to permanent operation of the material exhibit pitting corrosion leading to a complete destruction of the elements - Fig. 8.

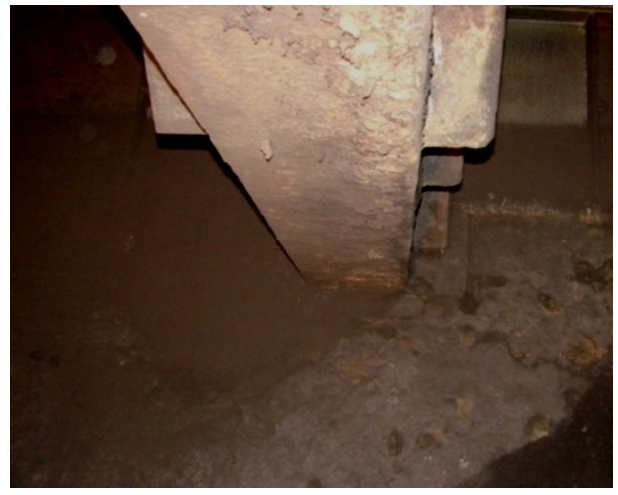

Fig. 7. Surface corrosion of the plain girder.

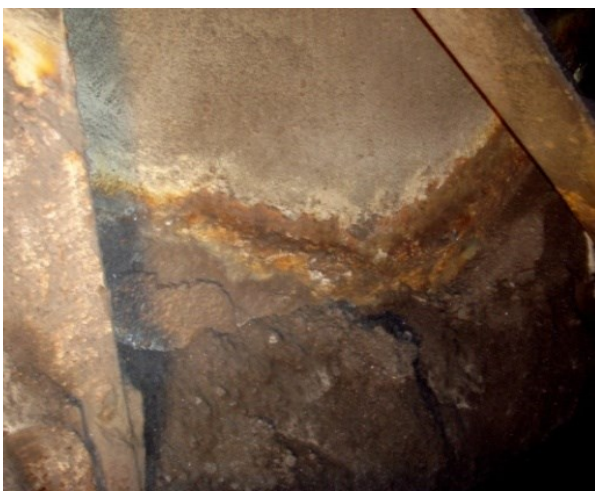

Fig. 8. Strong pitting corrosion of the steel sheet.

\subsection{Damages to external layer of the bunker's walls}

All external steel sheets and stiffening profiles have been damaged by surface corrosion, locally very strong and covering entire sheets and the line of joints (vertical and horizontal) - Fig. 9. In some places, where the corrosive damage was very extensive, new elements were welded. Unfortunately, those new elements were completely without anti-corrosion coating and corroded as first place (Fig. 10).

Pitting corrosion of the steel sheet - of a local nature - is also observed. In extreme cases, there are holes in the steel covering sheet (Fig. 11). 

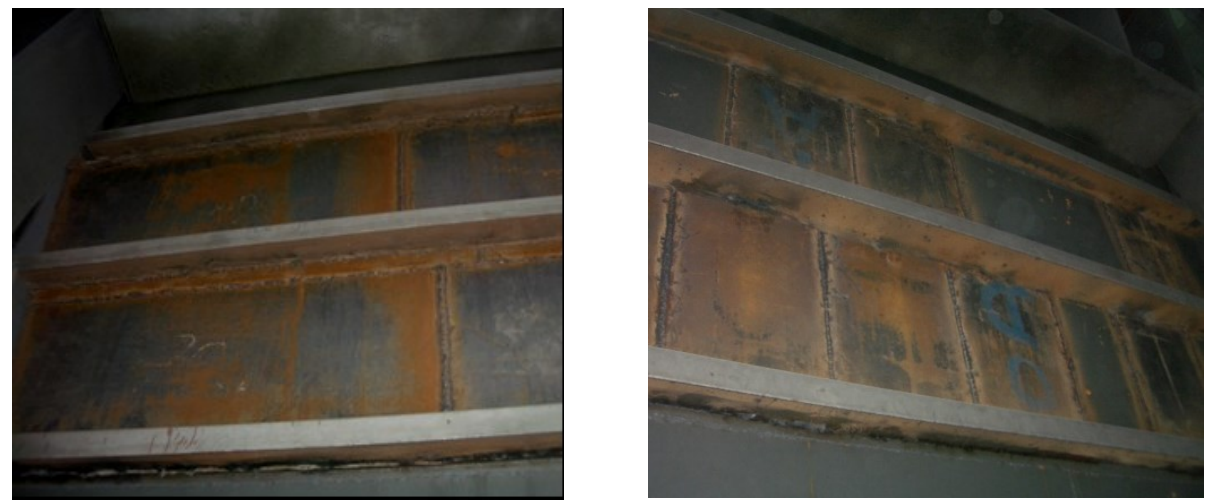

Fig. 9. Surface corrosion of the sheets and joints.
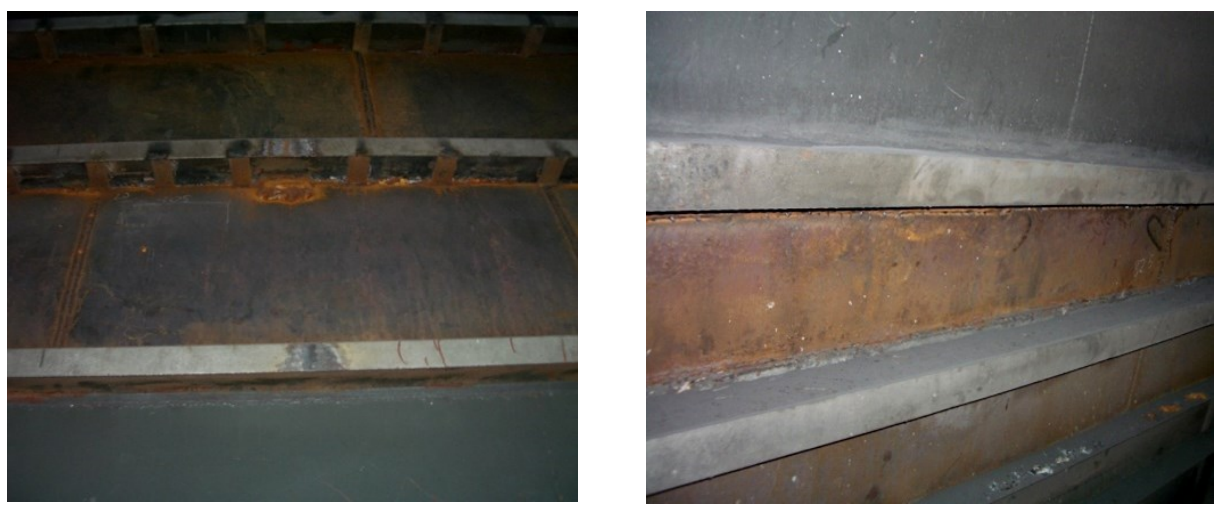

Fig. 10. Surface corrosion of new welded elements.

Damage within the hopper is primarily of the mechanical type with a local deformation of the surface. There are traces of hammer impact in order to break away the build-up material. These treatments caused destruction of the anti-corrosion layer, which consequently resulted in the acceleration of corrosion processes. In Fig. 12 surface and pitting corrosion is visible.

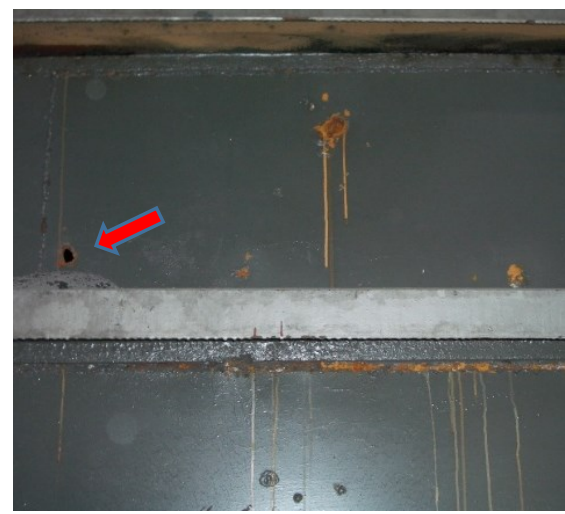

Fig. 11. Pitting corrosion and hole(marked by red arrow).

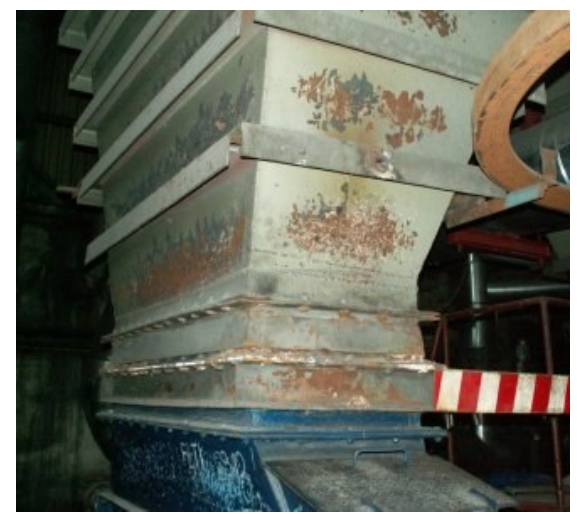

Fig. 12. Mechanical damage of the hopper's external surface. 


\subsection{Damage to concrete covering slab}

The concrete plate is supported on steel beams, which are covered with concrete in the middle part. Locally, this concrete layer is strongly damaged, mainly mechanically (Fig. 13), but also corrosive (elements exposed to direct action of coal water). Uncovered parts of the steel beams show signs of the surface corrosion.

The external layer of the plate, available from the top of the bunkers, is partially completely destroyed. The loosen parts of the floor are visible in Fig. 14. This situation results from the transport near the charging opening of heavy equipment and machines (for example for repairing conveyors). These actions were not planed in the exploration of the object and not foreseen during designing of this area of the structure.

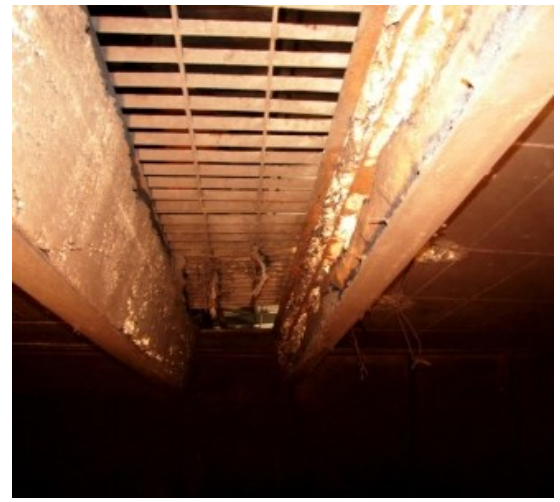

Fig. 13. Corrosion and mechanical damage of the beams supported cover plate.

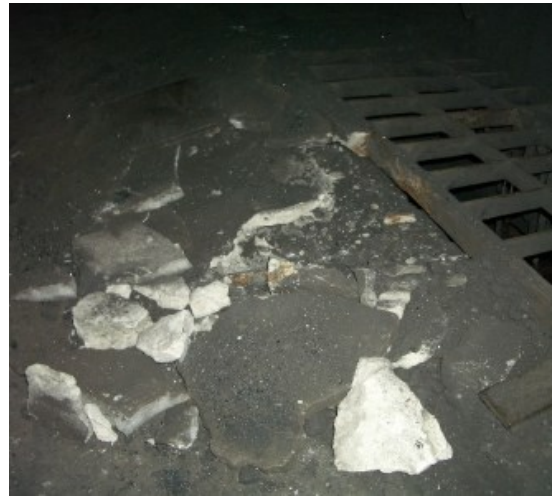

Fig. 14. Strong mechanical damage of the concrete floor.

\section{Discussion of problems of industrial structures on the example of coal bunkers for a power boiler}

The assessment of the technical condition of the structures located in industrial facilities is usually very complicated and problematic. This is due, on the one hand, to a limited access and ability to perform an appropriate inspection, on the other hand due to the existing of an unusual environment and working conditions. Those problems are analyzed below on the example of damage of a rather specific, mixed construction made of steel and reinforced concrete elements of coal bunkers to supply the boiler in the power plant.

The damage to the main structural elements of the analyzed coal bunkers, presented in $p$. 3 , can be broadly divided into three basic types listed below.

1. Mechanical damage indicated in steel structure and concrete infill walls resulting from the harmful actions of coal and coal fines on these structural elements. These activities include mechanical impacts of small coal lumps, abrasion of the upper surface of concrete and steel by coal dust, strong moving in the hoppers and also external operations enabling the tank to be emptied (hammer).

2. Advanced corrosion damages of both steel and concrete elements, resulting from the action of coal mine water. This water is transported along with coal and contains many aggressive chemical substances including sulphate $\mathrm{SO}_{4}{ }^{2-}$ and chloride $\mathrm{Cl}^{-}$ions, which are very hazardous for steel and concrete from the durability point of view. 
3. Damages caused during the operation of the facility due to improper ongoing control of the technical condition or no inspections at all of both the object and its individual structural elements. These are usually mechanical and corrosion damage to the elements, which were not captured at an early stage and led to the complete destruction of parts of the structure.

In many cases, the first and second groups of damage occur together and are present in all industrial objects. This damage increases with the time, because they are caused by the continuing impact of adverse factors (mechanical or chemical in nature). Very often, this damage cannot be seen and diagnosed from the outside of the object, because they arise within internal surfaces and structural elements, closed inside cubature structures. In the discussed case of coal-fired CHP plants, the largest mechanical and corrosive damage occurred on the internal elements of steel structure and concrete walls. They were caused by pouring material, which hits inappropriately protected elements (Fig. 13) and includes very aggressive for steel and concrete coal mine water (Fig. 6b, 7 and 8). Because the bunkers were constantly filled with material (coal, fined coal and coal sludge), it was not possible to see the damage during the normal operation of this industrial installation. With time, the intensity of this damage increased, while outside the bunker it was not very visible. The first visible damage on the external surface of the bunker (traces of pitting corrosion and holes in the plane of the shell - Fig. 11) indicates the poor condition of its internal elements. The full picture of damage to the interior of the bunker and the assessment of its technical condition was possible only during a short break in the operation of the power boiler, what was very problematic.

The third group of damage arises always during the operation of the object, which has not been subjected to adequate technical control and supervision. In the case in question, there was very serious damage of mixed nature - both mechanical (coal hits always in the same place) and corrosive, which, in a sufficiently long time, has led to the total destruction of steel beams (Fig. 5). The degree of damage is so significant that only way to repair is to build new elements into the supporting system. This and other damage (indicated below) require the object to be put out of service for a relatively long time, because the range of strengthening and repair works is huge. Other damage observed in bunkers, which results from the lack of proper inspection and periodical repairs, is strong surface corrosion on the external steel sheets (Fig. 9). To prevent this damage a prosaic action - cyclical renewal of anti-corrosion coatings - would be enough and could be carried out without empting the bunker and stopping the production. However, an extreme case of improper control of this object is corrosion of new welded elements (in most corroded places), which have no protection against corrosion and have been damaged immediately after their application (Fig. 9 and 10).

Another type of damages appearing in many industrial structures, but not observed here, results from errors and executive irregularities, arising at the stage of performing these structures (incorrect concrete filling, not appropriate compacting of concrete, not quite correct composition and/or care of concrete, etc.). Of course, this type of damage should be eliminated at the stage of building construction. A very detailed quality control of the construction works should be carried out, and all irregularities noted should be immediately and thoroughly repaired. Damage in the form of cavities and defects in concrete should be repaired using appropriate materials, techniques and repair technologies - appropriate to the target utility functions, loads and interactions characteristic of these elements and structures, e.g. providing increased resistance to aggressive corrosive effects of mine water contained in coal and post-flotation mud, or mechanical abrasion of sliding carbon coal on the walls of coal bunker funnels. Such operation is particularly important in the case of industrial facilities in which, due to the technological cycle being implemented, there is no access to the surface of the load-bearing structure elements - as in the coal-fired power plant boilers discussed above. 


\section{Conclusions}

Having the above considerations in mind, it should be assumed that in the case of analysing the technical condition of buildings and structures of an industrial nature, especially of cubature constructions with difficult or even impossible access to interior spaces, it is necessary to maintain cautious approach. Based on the above analyses, the following conclusions may be formulated:

1. Full and reliable assessment of the technical condition of the structure, especially the bunker-type or silos, is possible only after a comprehensive inventory of all damages of both the elements with trouble-free access from the outside, as well as parts and internal surfaces. It is therefore necessary to provide access to the interior of the object or construction after emptying its contents.

2. Reliance on the technical condition of elements and structures visible from outside, especially when during the operation of the facility the user made occasional temporary repairs, it may lead to erroneous inference about the actual condition of the given elements of the object. As a consequence, there may be a threat to the security of use, and importantly, without the user's awareness of the object.

3. Damage observed in industrial constructions is primarily due to the aggressive environment in which these objects work. Strong corrosion of concrete and steel, as well as mechanical damage resulting from the dynamic impact of, for example, stored material, in the absence of proper control and periodic repairs often lead to the complete destruction of the fragment, and even the entire structure. Repair of such damage in this type of facilities are possible only after temporarily excluding installations and objects from use, which is very often extremely difficult or generates huge costs.

4. In the case of construction and commissioning of new facilities, especially specific industrial facilities, it is necessary to ensure very high quality of works and reliable control. All executive irregularities lead to a significant acceleration of typical corrosion damage. Therefore, all structural problems should be repaired immediately after detection using technological and material solutions suitable both for a given type of construction, as well as target working conditions and load of these elements. 


\section{References}

1. ISO 2394:1998: General principles on reliability for structures

2. ISO 13822:2001: bases for design of structures - Assessment of existing structures

3. SAFERELNET: Thematic Network on Safety and Reliability of Industrial Products, Systems and Structures. Project Coordinator: Carlos Guedes Soares; http://mar.ist.utl.pt/saferelnet/ 2001-2005

4. Joint publication: M. Sýkora, Handbook on structural assessment of industrial heritage buildings. (Klokner Institute, Czech Technical University in Prague, 2010)

5. M. Brehm, H. Bolt, Framework for assessment and life extension of structures and industrial plants. (Proceedings of the SAMCO Summer Academy, Zell am See, Austria, 2005)

6. R. Holland, B.E. Montgomery-Smith, J.F.A. Moore, Appraisal \& Repair of Building Structures (Thomas Telford Ltd, London, 1992)

7. L. Addleson, Building failure: a guide to diagnosis, remedy and prevention. (Butterworth, Oxford, 1992)

8. Guideline: W. Rücker, F. Hille, R. Rohrmann, F08a Guideline for the Assessment of Existing Structures. SAMCO Final Report 2006 (Federal Institute of Materials Research and Testing, Berlin, Germany, 2006)

9. M. Holický, V. Návarová, R. Gottfried, M. Kronika, J. Marková, M. Sýkora, K. Jung, Basics for assessment of existing structures (Klokner Institute, Czech Technical University in Prague, Prague, 2013)

10. Joint publication: D. Diamantidis, Probabilistic Assessment of Existing Structures (Joint Committee on Structural Safety, 2001)

11. Guideline: Guide for the Structural Rehabilitation of Heritage Buildings. (CIB Publication 335, Prepared by CIB Commission W023 - Wall Structures, 2010).

12. D.K. Nordstrom, Elements, 7, pp. 393-398 (2011) 